\title{
Ambulatory anesthetic care in pediatric tonsillectomy: challenges and risks
}

This article was published in the following Dove Press journal:

Ambulatory Anesthesia

5 November 2015

Number of times this article has been viewed

\section{Corey Collins}

Massachusetts Eye and Ear Infirmary, Department of Anesthesiology, Harvard Medical School, Boston, MA, USA
Correspondence: Corey Collins Massachusetts Eye and Ear Infirmary, Department of Anesthesiology, Harvard Medical School, 243 Charles Street,

Boston, MA 02115, USA

$\mathrm{Tel}+$ I 6175733380

Fax +I 6175734033

Email corey_collins@meei.harvard.edu
Abstract: Pediatric tonsillectomy is a common surgery around the world. Surgical indications are obstructive sleep apnea and recurrent tonsillitis. Despite the frequency of tonsillectomy in children, most aspects of perioperative care are supported by scant evidence. Recent guidelines provide important recommendations although clinician adherence or awareness of published guidance is variable and inconsistent. Current guidelines establish criteria for screening children for post-tonsillectomy observation, though most are based on low-grade evidence or consensus. Current recommendations for admission are: age $<3$ years; significant obstructive sleep apnea; obesity; and significant comorbid medical conditions. Recent reports have challenged each criterion and recommend admission criteria that are based on clinically relevant risks or observed clinical events such as adverse respiratory events in the immediate recovery period. Morbidity and mortality are low though serious complications occur regularly and may be amenable to improvements in postoperative monitoring, improved analgesic regimens, and parental education. Careful consideration of risks attributable to individual patients is vital to determine overall suitability for ambulatory discharge.

Keywords: adverse airway events, complications, guidelines, mortality, OSA, pediatric anesthesia

\section{Introduction}

Pediatric tonsillectomy is routinely performed around the world, most often in the treatment of sleep-disordered breathing/obstructive sleep apnea (OSA) or recurrent pharyngitis. Children are most frequently discharged without overnight observation with low rates of serious complications. Recent analyses of available data sources have provided considerable guidance on the medical management of children following tonsillectomy, in some cases supporting the safety of ambulatory discharge, yet in others offering important warnings. In fact, the paucity of guidance based on high-quality evidence might remind clinicians that there is almost nothing "routine" about pediatric tonsillectomy.

\section{Epidemiology}

Over 560,000 ambulatory tonsillectomies were performed in the United States in 2006, affecting approximately $1 \%$ of all children under 16 years of age and accounting for $16 \%$ of all ambulatory surgery in this age group. ${ }^{1}$ Current estimates suggest that the number of tonsillectomies performed is increasing worldwide, perhaps due to increased awareness of the negative impact of untreated sleep apnea on childhood development, 
learning, and behavior. With an estimated current cost of $\$ 2,890$ for an uncomplicated outpatient tonsillectomy, this reflects a $\$ 1.73$ billion cost to the US health care system. ${ }^{2}$ A single night in a US hospital costs approximately \$4,293 according to a 2013 survey of health care payers; unplanned admission therefore would add significant costs.

Epidemiological trends in pediatric tonsillectomy have continuously changed over the past century, though the reasons for such changes have been poorly characterized. A significant increase in adenotonsillectomy (AT) in young children seems to mirror the increased diagnosis of sleep-disordered breathing. Overall, current data suggests a bimodal age distribution with the first peak between 5 and 8 years and a second peak between 17 and 21 years. Infectious indications have declined: while in $1970,88.4 \%$ of tonsillectomies or ATs were for infectious reasons, in 2005 this decreased to $23.2 \%$. Adolescent females are more likely to have AT for infectious reasons; rates for AT due to OSA are similar between young male and females. ${ }^{3}$

While tonsillectomy operations have been performed for over 2,500 years, evidence of efficacy has been scant. For most of the past century, authors have challenged the appropriateness of this surgery, its efficacy, and its safety, with some even calling it "ritualistic". ${ }^{4}$ In their important 2013 paper, Marcus et al provided the best evidence currently available to support the efficacy of tonsillectomy for the treatment of pediatric OSA. Four hundred and sixty-four children aged 5-9 years were randomized to either have surgery or nonsurgical medical management for sleep-studydocumented OSA. They found no significant difference in attention and cognitive function as a primary outcome for success at 7 months following randomization. They did note significant improvements in behavior ratings from caregivers, but not teachers, in the surgical cohort. In addition, surgery was associated with significantly greater improvements in symptoms of sleepiness, apnea-hypopnea index (AHI), and quality of life scores. Follow-up sleep study data was normalized in $79 \%$ of the surgical group compared to $46 \%$ of the nonsurgical group. Normalization of OSA was less common in blacks and obese children in both groups. ${ }^{5}$ This important data provides evidence to support the use of surgical intervention to improve the quality of life of children with OSA. Furthermore, it suggests that certain groups of children might derive less benefit from surgery.

Recurrent tonsillitis is the next most common indication for pediatric tonsillectomy. In a 2014 Cochrane Database of Systematic Reviews statement, Burton et al provide an analysis of available data. They noted only a modest benefit attributable to tonsillectomy on the reduction of frequency or severity of sore throats most consistently in children more severely affected. ${ }^{6}$ In a pragmatic randomized controlled trial with economic analysis, Lock et al randomized 268 children with recurrent sore throats to either surgery or medical management and recruited 461 children in a parallel nonrandomized cohort. ${ }^{7}$ Their data estimated a cost of $£ 261$ per sore throat avoided. Despite this cost, most children and parents exhibited strong preference for surgery and children randomized to surgery tended to experience better outcomes. After 2 years, these benefits were no longer significant.

\section{Guidelines for diagnosis}

Guidelines for the surgical indications for pediatric tonsillectomy have been published in a number of countries. The "Paradise Criteria" support surgery if a child experiences at least seven sore throats in the past year, five episodes in each of the past 2 years, or three episodes per year in the past three years. A sore throat is defined as throat pain with either a fever greater than $38.3^{\circ} \mathrm{C}$, cervical adenopathy, or a tonsillar exudate. ${ }^{8}$ These criteria were recommended in the 2011 American Academy of Otolaryngology-Head and Neck Surgeons (AAOHNS) Clinical practice guideline: tonsillectomy in children. ${ }^{9}$ Ten Statements were offered to assist in the clinical care of children and included recommendations: against routine antibiotic use; that dexamethasone should be administered to reduce pain and postoperative nausea and vomiting (PONV); that adequate analgesia should be ensured including consideration for the use of COX-2-inhibiting nonsteroidal anti-inflammatory drugs (NSAIDs) (excluding ketorolac); and that outcomes should be collected on post-tonsillectomy hemorrhage $(\mathrm{PTH})$ rates for all surgeons at least annually.

For children with suspected or confirmed OSA, surgery is indicated despite a lack of consensus on criteria for diagnosis. Polysomnography (PSG) remains the best test to quantify the severity of OSA, yet is employed in $\sim 10 \%$ of pediatric tonsillectomy patients before surgery. ${ }^{10}$ The AAO-HNS recommends $\mathrm{PSG}$ for children with significant comorbid conditions (obesity, Down syndrome, craniofacial abnormalities, neuromuscular disorders, sickle cell disease, or mucopolysaccharidosis) and suggests its use if discordance arises regarding surgical benefit based on tonsil size and clinical indicators. PSG data should be communicated to anesthesiologists before tonsillectomy to assist in perioperative planning and management. ${ }^{11}$

Risks associated with tonsillectomy are significant though serious adverse events (AEs) are relatively rare. 
The most commonly described complications include bleeding (1\%-5\%), ${ }^{12}$ pulmonary edema $(\sim 4 \%-10 \%),{ }^{13,14}$ respiratory complications (laryngospasm/bronchospasm/ hypoxemia), ${ }^{15,16}$ pain, ${ }^{17}$ nausea/vomiting, ${ }^{18,19}$ agitation, ${ }^{20,21}$ and burns. ${ }^{22}$ Rare events include pneumothorax, temporomandibular joint dysfunction, dental or vocal cord injuries, vascular injuries, or airway fires. Some complications may be related to underlying medical conditions (eg, more severe OSA has an increased association with post-tonsillectomy pulmonary edema ${ }^{14}$ ) while many are erratic and require clinical vigilance in all children. The knowledgeable clinician must be familiar with such perioperative challenges.

Overall mortality is difficult to quantitate due to limitations in data collection, inaccuracies in attribution of harm when liability cases are closed, voluntary reporting of critical events among clinicians, and problematic interpretation of data from government repositories. US mortality estimates from 1968 to 1972 ranged from one in 16,000 to one in $35,000 .{ }^{23}$ More recently, Windfuhr et al estimated a mortality rate of one in 16,129 based on data from Europe. ${ }^{24}$ Subramanyam et al reviewed a dataset from the LexisNexis ${ }^{\circledR}$ legal database and published details of closed settlement awards. Thirty-nine of 98 fatal claims were attributed to surgical causes with awards between $\$ 600,000$ and $\$ 2,331,002(n=7)$, whereas anesthesia-related claims were noted in 36 of 98 fatalities with awards from $\$ 600,000$ to $\$ 2,143,715(n=10)$. Nonfatal awards, however, resulted in monetary awards against anesthesiologists from $\$ 654,927$ to $\$ 25,689,179$ ( $n=7$ ), with the higher awards related to anoxic brain injuries related to airway management or perioperative respiratory monitoring. ${ }^{25}$ In an equally sober analysis, Coté et al used a survey tool and review of the American Society of Anesthesiologists (ASA) Closed Claims Database to assess the contemporary impact of tonsillectomy mortality on anesthesiologists. One hundred and eleven cases were analyzed with death (73/111) or serious neurological injury (13/111) noted. Locations of the events varied from operating room, postanesthesia care unit (PACU), in the hospital, or at home with no significant prevalence. Children at risk for OSA had higher complication rates related to apnea $(P=0.016)$ whereas other children were more likely to have bleeding complications $(P=0.006)$. Sixty-three events occurred within 24 hours of surgery, with 30 (48\%) occurring after discharge from the hospital. Risk for OSA did not impact timing of events. In two tragic examples, children died in the PACU because respiratory monitors were removed. The authors recommend careful screening of children for OSA risks, appropriate use of perioperative monitors throughout the perioperative period, and to be aware of the concomitant risks of obesity, OSA, and opioid sensitivity after tonsillectomy. ${ }^{26}$

Less serious complications occur more frequently in ambulatory tonsillectomy and provide data important to anesthesia management. Raman et al proposed guidelines for planned admission after tonsillectomy and AT. Before implementation of their guidelines, unplanned admission occurred in $2.38 \%$ of ambulatory cases related to PONV, respiratory issues, bleeding, and sleepiness. After implementation of the guidelines, $1.44 \%$ of ambulatory cases were admitted, exclusively related to nonadherence to guidelines and body mass index (BMI) of the children. Their criteria for admission after tonsillectomy are: age less than 3 years old; sleep study AHI $>10$; pulse oximetry reading $<80 \%$ during $\mathrm{PSG}$; end-tidal $\mathrm{CO}_{2}>50 \mathrm{mmHg}$ during PSG; obesity BMI $>95 \%$ (percentile for age); craniofacial syndromes (ie, Down syndrome, Pierre Robin syndrome, etc); significant comorbid conditions; asthma (moderate/severe); are cystic fibrosis. ${ }^{27}$ As demonstrated in this report and others, ${ }^{28}$ compliance with published guidelines remains a current challenge among clinicians and represents an important area for quality improvement throughout health care.

\section{Postoperative admission}

Tweedie et al reported a series of 1,735 consecutive children aged 4-197 months, (median =46 months) admitted for tonsillectomy at a referral pediatric center and found a same-day discharge was achieved in 300 children. Of these children, $61.4 \%$ had a diagnosis of OSA, though only $15 \%$ had PSG data. One thousand and eighty-two children required onenight observation while $\sim 1 \%$ required unplanned pediatric intensive care unit (PICU) admission. The need for observation was related to comorbidities such as mucopolysaccharidosis, congenital heart disease, or Down syndrome. Overall complications occurred in $2.4 \%$ of patients, mostly in high-risk children with comorbidities. ${ }^{29}$ These data suggest that typical admission criteria might be overly conservative and most children, even those with significant medical comorbidities, do not exhibit clinically significant posttonsillectomy AEs.

While age $<3$ years has been a consistent threshold for admission for decades, numerous reports challenge its validity in select children. In 1997, Mitchell et al reported 131 children aged 16-36 months with only ten patients (mean age 28 months) admitted due to early complications (poor oral intake). Children with OSA were excluded. ${ }^{30}$ More recently, Belyea reported a case-control study on tonsillectomy patients under 3 years and found no significant 
differences in the complication rates. ${ }^{31}$ One hundred and twenty-seven children under 3 years of age were matched to the same number of children between the ages of 3 and 4 years. Their study group had a $3.1 \%$ early complication rate (typically respiratory) and a 6.3\% late complication rate (bleeding and dehydration) compared to the control group's $3.1 \%$ early and 5.5\% late complications (not significant). OSA was not documented by PSG in any of their patients and all surgeries occurred in a single pediatric hospital. In contrast, data from McCormick et al provides supporting evidence that young children may warrant admission after tonsillectomy. ${ }^{32}$ Nine hundred and ninety-three charts were retrospectively reviewed (mean age 2.9 years); 700 children were admitted and the remainder discharged. Significant predictors for overall complications $(3.5 \%)$ on the first postoperative day were nasal obstruction, gastroesophageal reflux disease, prematurity, and a history of cardiovascular anomalies. Significant predictors of airway complications $(2.3 \%)$ on postoperative day $0-1$ were younger age (1-2 years old), larger adenoid size, nasal obstruction, and a history of cardiovascular anomalies. Overall, the complication rate was $9.9 \%$ and included airway obstruction $(n=14)$, desaturations $(n=9)$, hemorrhage $(n=7)$, and return to emergency ward for poor oral intake after discharge $(n=5)$. Three children required postoperative endotracheal intubation for airway support. In this cohort of very young patients, only children over 3 years of age were discharged on the same day of surgery with significantly lower complication rates.

Routine admission for children under 3 years remains the current recommendation, though well-selected children that experience uneventful surgery and early recovery may warrant consideration for ambulatory discharge. Further evidence is however needed to fully characterize the safety of this practice.

Looking at preoperative intensive care screening, Theilhaber et al closely monitored children planned for PICU admission after tonsillectomy for specific clinical events immediately after surgery that was associated with subsequent adverse clinical events in the PICU. Out of 72 children with a mean age of 2.8 years, 46 had significant comorbidities and severe OSA by PSG, and 29 mild AEs were experienced in 26 children. A Mild AE was defined as oxygen saturation $\left[\mathrm{SpO}_{2}\right], 95 \%$ treated by administration of supplemental $\mathrm{O}_{2}$ or repositioning of the patient to improve the airway, while a severe AE was defined as any of: desaturation treated by bag and mask ventilation; continuous positive airway pressure or bi-level noninvasive ventilation; placement of oropharyngeal airway; reintubation; or unplanned admission to the intensive care unit. Since a significant majority of children that went on to experience severe adverse clinical events in the PICU also experienced at least mild AEs in the first hours after surgery, typically in the PACU, the authors suggest that a period of prolonged monitoring in the PACU for AEs permits adequate selection of children at need for PICU-level care. They report a $98.3 \%$ negative predictive value for children that do not experience AEs in the early postoperative period. These data suggest that safe ambulatory discharge of some high-risk children might be appropriate after uncomplicated tonsillectomy and 2 hours of uneventful observation in the PACU. ${ }^{33}$

In a prospective trial of 329 consecutive children that presented for tonsillectomy after PSG-confirmed OSA, significant associations were found between PSG data (ie, lowest $\left.\mathrm{SpO}_{2}, P<0.005\right)$, black race $(P=0.039)$, and age $<3$ years $(P=0.003)$ and respiratory complications. Thongyam et al reported no significant factors between PSG data, a number of social factors, and nonrespiratory complications. These data suggest that current guidelines from the American Academy of Pediatrics and AAO-HNS rely upon demographic data more than PSG data to screen for ambulatory discharge; at least for the relatively high-risk cohort of tonsillectomy patients, PSG data seems more accurate for planning discharge. Specifically, the authors propose age $<3$ years, nadir $\mathrm{SpO}_{2} \leq 80 \%$, and peak end-tidal $\mathrm{CO}_{2} \geq 60 \mathrm{mmHg}$ for admission criteria. ${ }^{15}$

Data from Baguley et al further supports a clinicallyguided discharge approach. One hundred patient charts were reviewed after tonsillectomy. All children had mild to moderately-severe OSA by PSG. Ages were 3-15 years (mean 5.9 years). No severe AEs occurred and oxygen supplementation was the only intervention for mild desaturation in seven children. One child experienced laryngospasm that required muscle relaxation for rescue in the recovery room. Only three children continued to require supplemental oxygen 6 hours post-tonsillectomy, suggesting that admission status to reduce risk of postoperative hypoxemia can be reasonably excluded after an initial uneventful recovery period of 4-6 hours. $^{34}$

\section{Does admission reduce complication rates?}

Most serious complications would not be avoided with postoperative admission in properly screened children as suggested by a number of sources. Windfuhr et al reported voluntarily submitted survey data from Germany on lethal PTHs and opined that "inpatient observation could not 
eliminate lethal outcome in some cases" due to highly variable onset of PTH and the erratic recognition of occult bleeding in children. Only $6 / 52$ bleeding deaths occurred in the first 24 hours. Overall, 19 children died with recurrent bleeding episodes. Recurrent hemorrhage was associated with highest risk of death. ${ }^{35}$ Coté et al reported that 16 post-tonsillectomy deaths would have been prevented if proper monitoring had continued throughout the immediate recovery period. AEs were more likely to occur in children at high risk for OSA. Proper screening mechanisms and adherence to good monitoring practice in the immediate recovery period should take priority over conservative admission criteria. ${ }^{26}$

In a survey of US otolaryngologists, Goldman et al reviewed 51 deaths and four severe anoxic brain injuries reported voluntarily. Sixty percent of deaths occurred in the first 2 postoperative days; $51.7 \%$ occurred in the hospital, $28.8 \%$ during the initial admission after surgery, and $11.9 \%$ after readmission. Apnea contributed to $59.3 \%$ of events, medication error in $20.3 \%$, and bleeding in $15.3 \%$. Surgeons performing less than 200 tonsillectomies per year were significantly more likely to report an event. In contrast to Coté et al, no association between OSA and AEs was found. Neurological or cardiopulmonary disease, obesity, and drugrelated errors, especially related to opiates, were significantly associated with events. ${ }^{36}$ While preoperative screening criteria can attempt to identify children with these and other risk factors, it remains unclear whether admission would have prevented deaths in these reported cases.

\section{Current admission guidelines}

The French Society of Anesthesia and Intensive Care recommends the following criteria for ambulatory discharge after pediatric tonsillectomy: age $>3$ years; ASA Physical Status Classification (PS) I-II; no comorbidity liable to exacerbate the respiratory risks; and no hemostasis abnormality. They further recommend social criteria such as family surveillance at home; compliance with postoperative prescriptions; and understanding of procedures in case of postoperative complications. Other criteria include specific suggestions regarding communication among the surgical team members, plan for analgesia, PONV prophylaxis, and other items. ${ }^{37} \mathrm{In}$ contrast, no similar consensus guideline has been published in the USA. Typical published US guidelines for admission include age $<3$ years, severe OSA (eg, AHI $>10$ ), obesity (eg, BMI $>95$ th percentile for age), craniofacial syndromes (eg, trisomy 21), and significant systemic comorbid conditions (eg, congenital heart disease, sickle-cell disease, insulin-dependent diabetes). ${ }^{27}$ The AAO-HNS recommends admission of children with OSA, age $<3$ years, and AHI $>10 \pm \mathrm{SpO}_{2}$ nadir $<80 \%$. $^{11}$

\section{Clinical variation in current practice}

Despite, or perhaps, due to the many sources of guidance, significant practice variability occurs across the USA. Mahant et al completed a retrospective cohort study of regional variability in the care of low-risk children having tonsillectomy at pediatric hospitals. While strong consensus statements recommend the administration of dexamethasone, administration rates varied from $0.3 \%$ to $98.8 \%$ (median 76.2\%). Similarly, despite recommendations not to administer routine perioperative antibiotics, the authors observed administration rates of $2.7 \%-96.7 \%$ (median $16.3 \%$ ). They noted a 30 -day readmission rate of $7.8 \%$, most commonly for bleeding (3.0\%) and dehydration/vomiting $(2.2 \%)$. Readmission for dehydration and vomiting usually occurred within 48 hours after surgery at a rate of 4.55 per 1,000 hospital-days' follow-up. Bleeding was most likely to cause readmission at postoperative day 6-7 at a rate of 4.23 per 1,000 days of follow-up. Ninety-seven point eight percent of all readmission occurred by POD 15. These data suggest that there is important variability in the adherence to evidence-based and widely accepted guidelines on the perioperative care of the pediatric tonsillectomy patient in the USA. The readmission data might also provide postoperative outcome quality metrics. Dehydration and PONV are significant reasons for readmission, and patient evaluation and parental education should account for a patient's risks for poor oral fluid intake following discharge. ${ }^{38}$

Current pediatric anesthesia practice is highly variable and individual clinician behavior can be difficult to change. In 2007, Abu-Shahwan published a survey of Canadian pediatric anesthesiologists that demonstrated a wide variability in the willingness to anesthetize children with various clinical conditions for routine surgery. Given 20 scenarios, there was consensus to proceed in seven and cancel in one, and there was no consensus in the remainder. Examples of ambulatory tonsillectomy scenarios with no consensus include in a healthy 4-year-old child with fever of $38^{\circ} \mathrm{C}$ and nasal discharge ( $66 \%$ would proceed), a healthy asymptomatic 5-year-old child with OSA (40\% would proceed), or a 4-year-old child with insulin-dependent diabetes mellitus (49\% would proceed). ${ }^{39}$ Clarke et al reported very poor compliance with National Health Service guidelines intended to prevent the spread of variant Creutzfeldt-Jakob disease through the use of disposable and protective equipment. Eighty-four percent of survey respondents disagreed with 
the guidelines, full compliance was reported in $16 \%$ and $38 \%$ were unaware the guidelines existed 4 years after publication. ${ }^{40}$ On the other hand, the publication of the AAOHNS guidelines with strong recommendation against the routine use of antibiotics in pediatric tonsillectomy patients resulted in an $86.5 \%$ drop in perioperative antibiotic use in one study. ${ }^{41}$ As previously discussed, attempts to implement local guidelines for admission after tonsillectomy can be hindered by clinician noncompliance as demonstrated by a $30 \%$ nonadherence rate reported by Raman et al. ${ }^{27}$ Despite the emergence of evidence-based clinical practice guidelines, ongoing quality systems will need to focus on physician compliance to address variability in adherence and attitudes about relevance to specific patient care.

\section{Variability in pain management}

Consider the role of COX-2 inhibitors/NSAIDs. A Cochrane Database review, ${ }^{42}$ national pain guidelines from Sweden, ${ }^{43}$ and recent reports demonstrate no significant increased bleeding rates in children that receive ibuprofen, diclofenac, or celecoxib. ${ }^{44}$ Ibuprofen significantly decreased the risk for $\mathrm{PONV}^{42}$ and emerging data suggests that reduction in the use of opiates for post-tonsillectomy pain should contribute to increased ambulatory discharge, ${ }^{43,44}$ decrease revisits for pain control, ${ }^{48}$ or improve pain management now that administration of codeine is strongly discouraged. ${ }^{49}$ In a 2009 survey from the United Kingdom, $50 \%$ of respondents used rectal diclofenac routinely, and $20 \%$ and $16 \%$ administered ibuprofen preoperatively and for analgesia after discharge, respectively. ${ }^{50}$ As suggested in their 2014 "best practice" manuscript, Yellon et al state "Statistically significant yet limited existing evidence suggests that ibuprofen is safe to use concomitantly or as a second-line medication". ${ }^{51}$ Moss reported that a single intravenous dose of ibuprofen (10 mg/ $\mathrm{kg}$ ) at induction significantly decreased perioperative fentanyl use. ${ }^{45}$ Despite the long-standing belief that ketorolac is unique among NSAID medication in causing an increased risk of PTH, Chan and Parikh recently published a systematic review and meta-analysis, and concluded that a single intraoperative dose of ketorolac did not contribute to increased PTH in children (adults had a fivefold increased risk of PTH after receiving ketorolac). ${ }^{52}$ Most recently, Kelly et al randomized 91 children aged 1-9 years to receive acetaminophen with either per ora morphine $(0.2-0.5 \mathrm{mg} / \mathrm{kg}$ every 4 hours pro re nata) or ibuprofen ( $10 \mathrm{mg} / \mathrm{kg}$ every 6 hours pro re nata) after discharge home. Parents administered analgesics on average for $\sim 4$ days. While there were no significant differences in overall PTH, analgesic efficacy, or adverse drug events, the ibuprofen cohort had significant improvement in nocturnal desaturation rates on the first night after surgery $(86 \%$ versus $14 \%$ in the morphine arm) and the trial was halted before completion. ${ }^{44}$ NSAID medications are effective in the management of post-tonsillectomy pain though important concerns regarding bleeding risks will likely need further study before wider use, especially in the USA.

Currently available pain management regimens are highly variable, especially after discharge. ${ }^{18,53,54}$ Fortier et al used a standardized anesthetic regimen to assess pain after tonsillectomy. Eighty-six percent of children were rated to have "significant" pain yet only $24 \%$ of children received zero to one analgesic dose in the first 24-hour period after surgery. Even after 7 days, almost $50 \%$ of parents still reported "significant" pain in their children. ${ }^{56}$ The authors concluded that significant work is needed to improve the management of pain in children after tonsillectomy. ${ }^{56}$ Lennon et al describe poor parental compliance with prescribed analgesia after tonsillectomy with daily dosing of paracetamol from 12.5 to $111 \mathrm{mg} / \mathrm{kg} /$ day (prescribed dose was $60 \mathrm{mg} / \mathrm{kg} /$ day). Twenty-two point seven percent of parents reported compliance with the prescribed analgesia regimen. ${ }^{57}$ Given that up to $60 \%$ of parents visit their child's pediatrician after tonsillectomy due to concerns including pain management, there is an important cost associated with the erratic management of post-tonsillectomy pain.

Recently, numerous techniques for analgesia have been studied including: injection of local anesthetics, ${ }^{58}$ aromatherapy, ${ }^{59}$ intracapsular injection, rectal or intravenous administration of ketamine ${ }^{60}$ topical honey, ${ }^{61}$ oral prednisolone, ${ }^{62}$ topical sucralfate, ${ }^{63}$ and dexmedetomidine. ${ }^{64,65}$ These small studies reflect the intense efforts to improve the management of pain in these children, but also underscore the lack of significant evidence available to clinicians to decide what is "best". Efforts to reduce the reliance on opiates seem appropriate considering the risks of increased PONV, respiratory depression, sedation, and unpredictable pharmacokinetics in children. Recent advances in genetic analysis and opiate receptors may provide important safety benefits in the near future when opiates are considered for pediatric patients. For example, Mamie et al recently published the first report of a genetic basis for postsurgical pain variability in children after orthopedic and abdominal surgery. ${ }^{66}$ In the future, such analysis might permit selection of an opiate with specific safety margins for a child to minimize risks while improving analgesia.

\section{Conclusion}

Same-day discharge after pediatric tonsillectomy appears to be a safe and reasonable approach to this common surgery 
in properly screened children. The Supplementary material summarizes recommendations. Clinicians responsible for the preoperative selection of these patients must remain vigilant for risks related to unplanned admissions and serious complications. The current available literature on the topic of risk assessment, prediction, and modification is remarkably scant despite decades of serious research and inquiry around the world. Emerging clinical practice guidelines and national consensus statements have begun to impact practice and certain outcomes; physician noncompliance remains an important factor contributing to slow implementation. Pain management is a significant problem with generally poor parental preparation for effective analgesia at home. Post-tonsillectomy guidelines should be followed in the absence of specific, patient-related countermands. Children with significant OSA have important risks to consider.

\section{Disclosure}

The author reports no conflicts of interest in this work.

\section{References}

1. DeFrances CJ, Cullen KA, Kozak LJ. National Hospital Discharge Survey: 2005 annual summary with detailed diagnosis and procedure data. Vital Health Stat 13. 2007(165):1-209.

2. Healthcare Bluebook: Cost of tonsillectomy [webpage on the Internet]. Brentwood: CAREOperative. Available from: https://healthcarebluebook.com/page_ProcedureDetails.aspx $? \mathrm{id}=60 \&$ dataset $=\mathrm{MD}$ $\& \mathrm{~g}=$ Tonsillectomy. Accessed.

3. Erickson BK, Larson DR, St Sauver JL, Meverden RA, Orvidas LJ. Changes in incidence and indications of tonsillectomy and adenotonsillectomy, 1970-2005. Otolaryngol Head Neck Surg. 2009;140(6): 894-901.

4. Bolande RP. Ritualistic surgery - circumcision and tonsillectomy. N Engl J Med. 1969;280(11):591-596.

5. Marcus CL, Moore RH, Rosen CL, et al. A randomized trial of adenotonsillectomy for childhood sleep apnea. N Engl J Med. 2013;368(25): 2366-2376.

6. Burton MJ, Glasziou PP, Chong LY, Venekamp RP. Tonsillectomy or adenotonsillectomy versus non-surgical treatment for chronic/recurrent acute tonsillitis. Cochrane Database Syst Rev. 2014;11:CD001802.

7. Lock C, Wilson J, Steen N, Eccles M, Mason H, Carrie S, et al. North of England and Scotland Study of Tonsillectomy and Adenotonsillectomy in children (NESSTAC) : a pragmatic randomised controlled trial with a parallel non-randomised preference study. Health Technol Assess 2010;14(13)

8. Paradise JL, Bluestone CD, Colborn DK, Bernard BS, Rockette HE, Kurs-Lasky M. Tonsillectomy and adenotonsillectomy for recurrent throat infection in moderately affected children. Pediatrics. 2002; 110(1 Pt 1):7-15.

9. Baugh RF, Archer SM, Mitchell RB, et al. Clinical practice guideline: tonsillectomy in children. Otolaryngol Head Neck Surg. 2011; 144(1 Suppl):S1-S30.

10. Mitchell RB, Pereira KD, Friedman NR. Sleep-disordered breathing in children: survey of current practice. Laryngoscope. 2006;116(6): 956-958.

11. Roland PS, Rosenfeld RM, Brooks LJ, et al. Clinical practice guideline: Polysomnography for sleep-disordered breathing prior to tonsillectomy in children. Otolaryngol Head Neck Surg. 2011;145(1 Suppl):S1-S15.
12. Isaacson G. Pediatric tonsillectomy: an evidence-based approach. Otolaryngol Clin North Am. 2014;47(5):673-690.

13. Thiagarajan RR, Laussen PC. Negative pressure pulmonary edema in children - pathogenesis and clinical management. Paediatr Anaesth. 2007;17(4):307-310.

14. Sonsuwan N, Pornlert A, Sawanyawisuth K. Risk factors for acute pulmonary edema after adenotonsillectomy in children. Auris Nasus Larynx. 2014;41(4):373-375.

15. Thongyam A, Marcus CL, Lockman JL, et al. Predictors of perioperative complications in higher risk children after adenotonsillectomy for obstructive sleep apnea: a prospective study. Otolaryngol Head Neck Surg. 2014;151(6):1046-1054.

16. von Ungern-Sternberg BS. Respiratory complications in the pediatric postanesthesia care unit. Anesthesiol Clin. 2014;32(1):45-61.

17. Lauder G, Emmott A. Confronting the challenges of effective pain management in children following tonsillectomy. Int $J$ Pediatr Otorhinolaryngol. 2014;78(11):1813-1827.

18. Stanko D, Bergesio R, Davies K, Hegarty M, von Ungern-Sternberg BS. Postoperative pain, nausea and vomiting following adeno-tonsillectomy a long-term follow-up. Paediatr Anaesth. 2013;23(8):690-696.

19. Bolton CM, Myles PS, Nolan T, Sterne JA. Prophylaxis of postoperative vomiting in children undergoing tonsillectomy: a systematic review and meta-analysis. Br J Anaesth. 2006;97(5):593-604.

20. Edler AA, Mariano ER, Golianu B, Kuan C, Pentcheva K. An analysis of factors influencing postanesthesia recovery after pediatric ambulatory tonsillectomy and adenoidectomy. Anesth Analg. 2007;104(4):784-789.

21. Pieters BJ, Penn E, Nicklaus P, Bruegger D, Mehta B, Weatherly R. Emergence delirium and postoperative pain in children undergoing adenotonsillectomy: a comparison of propofol vs sevoflurane anesthesia. Paediatr Anaesth. 2010;20(10):944-950.

22. Subramanyam R, Varughese A, Willging JP, Sadhasivam S. Future of pediatric tonsillectomy and perioperative outcomes. Int J Pediatr Otorhinolaryngol. 2013;77(2):194-199.

23. Pratt LW, Gallagher RA. Tonsillectomy and adenoidectomy: incidence and mortality, 1968-1972. Otolaryngol Head Neck Surg (1979). 1979;87(2):159-166.

24. Windfuhr JP, Schloendorff G, Sesterhenn AM, Prescher A, Kremer B. A devastating outcome after adenoidectomy and tonsillectomy: ideas for improved prevention and management. Otolaryngol Head Neck Surg. 2009;140(2):191-196.

25. Subramanyam R, Chidambaran V, Ding L, Myer CM 3rd, Sadhasivam S. Anesthesia- and opioids-related malpractice claims following tonsillectomy in USA: LexisNexis claims database 1984-2012. Paediatr Anaesth. 2014;24(4):412-420.

26. Coté CJ, Posner KL, Domino KB. Death or neurologic injury after tonsillectomy in children with a focus on obstructive sleep apnea: houston, we have a problem! Anesth Analg. 2014;118(6):1276-1283.

27. Raman VT, Jatana KR, Elmaraghy CA, Tobias JD. Guidelines to decrease unanticipated hospital admission following adenotonsillectomy in the pediatric population. Int $J$ Pediatr Otorhinolaryngol. 2014;78(1):19-22.

28. Chou AF, Vaughn TE, McCoy KD, Doebbeling BN. Implementation of evidence-based practices: Applying a goal commitment framework. Health Care Manage Rev. 2011;36(1):4-17.

29. Tweedie DJ, Bajaj Y, Ifeacho SN, et al. Peri-operative complications after adenotonsillectomy in a UK pediatric tertiary referral centre. Int J Pediatr Otorhinolaryngol. 2012;76(6):809-815.

30. Mitchell RB, Pereira KD, Friedman NR, Lazar RH. Outpatient adenotonsillectomy. Is it safe in children younger than 3 years? Arch Otolaryngol Head Neck Surg. 1997;123(7):681-683.

31. Belyea J, Chang Y, Rigby MH, Corsten G, Hong P. Post-tonsillectomy complications in children less than three years of age: A case-control study. Int J Pediatr Otorhinolaryngol. 2014;78(5):871-874.

32. McCormick ME, Sheyn A, Haupert M, Thomas R, Folbe AJ. Predicting complications after adenotonsillectomy in children 3 years old and younger. Int J Pediatr Otorhinolaryngol. 2011;75(11):1391-1394. 
33. Theilhaber M, Arachchi S, Armstrong DS, Davey MJ, Nixon GM. Routine post-operative intensive care is not necessary for children with obstructive sleep apnea at high risk after adenotonsillectomy. Int J Pediatr Otorhinolaryngol. 2014;78(5):744-747.

34. Baguley KE, Cheng AT, Castro C, Wainbergas N, Waters KA. Is day stay adenotonsillectomy safe in children with mild to moderate obstructive sleep apnoea? A retrospective review of 100 patients. Int $J$ Pediatr Otorhinolaryngol. 2014;78(1):71-74.

35. Windfuhr JP, Schloendorff G, Baburi D, Kremer B. Serious posttonsillectomy hemorrhage with and without lethal outcome in children and adolescents. Int J Pediatr Otorhinolaryngol. 2008;72(7):1029-1040.

36. Goldman JL, Baugh RF, Davies L, et al. Mortality and major morbidity after tonsillectomy: etiologic factors and strategies for prevention. Laryngoscope. 2013;123(10):2544-2553.

37. Lescanne E, Chiron B, Constant I, et al. Pediatric tonsillectomy: clinical practice guidelines. Eur Ann Otorhinolaryngol Head Neck Dis. 2012;129(5):264-271

38. Mahant S, Keren R, Localio R, et al. Variation in quality of tonsillectomy perioperative care and revisit rates in children's hospitals. Pediatrics. 2014;133(2):280-288.

39. Abu-Shahwan I. Ambulatory anesthesia and the lack of consensus among Canadian pediatric anesthesiologists: a survey. Paediatr Anaesth. 2007;17(3):223-229.

40. Clarke MB, Forster P, Cook TM. Airway management for tonsillectomy: a national survey of UK practice. Br J Anaesth. 2007;99(3):425-428.

41. Milder EA, Rizzi MD, Morales KH, Ross RK, Lautenbach E, Gerber JS. Impact of a new practice guideline on antibiotic use with pediatric tonsillectomy. JAMA Otolaryngol Head Neck Surg. 2015;141(5):410-416.

42. Lewis SR, Nicholson A, Cardwell ME, Siviter G, Smith AF. Nonsteroidal anti-inflammatory drugs and perioperative bleeding in paediatric tonsillectomy. Cochrane Database Syst Rev. 2013;7:CD003591.

43. Ericsson E, Brattwall M, Lundeberg S. Swedish guidelines for the treatment of pain in tonsil surgery in pediatric patients up to 18 years. Int J Pediatr Otorhinolaryngol. 2015;79(4):443-450.

44. Kelly LE, Sommer DD, Ramakrishna J, et al. Morphine or Ibuprofen for post-tonsillectomy analgesia: a randomized trial. Pediatrics. 2015;135(2):307-313

45. Moss JR, Watcha MF, Bendel LP, McCarthy DL, Witham SL, Glover CD. A multicenter, randomized, double-blind placebo-controlled, single dose trial of the safety and efficacy of intravenous ibuprofen for treatment of pain in pediatric patients undergoing tonsillectomy. Paediatr Anaesth. 2014;24(5):483-489.

46. Mattos JL, Robison JG, Greenberg J, Yellon RF. Acetaminophen plus ibuprofen versus opioids for treatment of post-tonsillectomy pain in children. Int J Pediatr Otorhinolaryngol. 2014;78(10):1671-1676.

47. Jeyakumar A, Brickman TM, Williamson ME, et al. Nonsteroidal antiinflammatory drugs and postoperative bleeding following adenotonsillectomy in pediatric patients. Arch Otolaryngol Head Neck Surg. 2008; 134(1):24-27.

48. Bedwell JR, Pierce M, Levy M, Shah RK. Ibuprofen with acetaminophen for postoperative pain control following tonsillectomy does not increase emergency department utilization. Otolaryngol Head Neck Surg. 2014;151(6):963-966.

49. Tan KW, Martin S, Bell G. Paediatric codeine use after adenotonsillectomy. Anaesthesia. 2014;69(10):1179-1180.
50. Allford M, Guruswamy V. A national survey of the anesthetic management of tonsillectomy surgery in children. Paediatr Anaesth. 2009;19(2):145-152.

51. Yellon RF, Kenna MA, Cladis FP, Mcghee W, Davis PJ. What is the best non-codeine postadenotonsillectomy pain management for children? Laryngoscope. 2014;124(8):1737-1738.

52. Chan DK, Parikh SR. Perioperative ketorolac increases post-tonsillectomy hemorrhage in adults but not children. Laryngoscope. 2014;124(8): 1789-1793.

53. Guntinas-Lichius O, Volk GF, Geissler K, Komann M, Meissner W. Pain after pediatric otorhinolaryngologic surgery: a prospective multi-center trial. Eur Arch Otorhinolaryngol. 2014;271(7):2049-2060.

54. Bean-Lijewski JD, Kruitbosch SH, Hutchinson L, Browne B. Posttonsillectomy pain management in children: can we do better? Otolaryngol Head Neck Surg. 2007;137(4):545-551.

55. Lee WC, Sharp JF. Complications of paediatric tonsillectomy post-discharge. J Laryngol Otol. 1996;110(2):136-140.

56. Fortier MA, MacLaren JE, Martin SR, Perret-Karimi D, Kain ZN. Pediatric pain after ambulatory surgery: where's the medication? Pediatrics. 2009;124(4):e588-e595.

57. Lennon P, Amin M, Colreavy MP. A prospective study of parents' compliance with their child's prescribed analgesia following tonsillectomy. Ear Nose Throat J. 2013;92(3):134-140.

58. Zhang X, Xu Y, Li P. [Effects of bupivacaine versus lidocaine infiltration on postoperative analgesia in pediatric tonsillectomy patients]. Lin Chung Er Bi Yan Hou Tou Jing Wai Ke Za Zhi. 2014;28(3):148-150. Chinese.

59. Soltani R, Soheilipour S, Hajhashemi V, Asghari G, Bagheri M, Molavi M. Evaluation of the effect of aromatherapy with lavender essential oil on post-tonsillectomy pain in pediatric patients: a randomized controlled trial. Int J Pediatr Otorhinolaryngol. 2013;77(9): 1579-1581.

60. Cho HK, Kim KW, Jeong YM, Lee HS, Lee YJ, Hwang SH. Efficacy of ketamine in improving pain after tonsillectomy in children: meta-analysis. PLoS One. 2014;9(6):e101259.

61. Ozlugedik S, Genc S, Unal A, Elhan AH, Tezer M, Titiz A. Can postoperative pains following tonsillectomy be relieved by honey? A prospective, randomized, placebo controlled preliminary study. Int J Pediatr Otorhinolaryngol. 2006;70(11):1929-1934.

62. Park SK, Kim J, Kim JM, Yeon JY, Shim WS, Lee DW. Effects of oral prednisolone on recovery after tonsillectomy. Laryngoscope. 2015;125(1):111-117.

63. Miura MS, Saleh C, de Andrade M, Assmann M, Ayres M, Lubianca Neto JF. Topical sucralfate in post-adenotonsillectomy analgesia in children: a double-blind randomized clinical trial. Otolaryngol Head Neck Surg. 2009;141(3):322-328.

64. Pestieau SR, Quezado ZM, Johnson YJ, et al. High-dose dexmedetomidine increases the opioid-free interval and decreases opioid requirement after tonsillectomy in children. Can J Anaesth. 2011; 58(6):540-550.

65. Olutoye O, Kim T, Giannoni C, Stayer S. Dexmedetomidine as an analgesic for pediatric tonsillectomy and adenoidectomy. Paediatr Anaesth. 2007; 17(10):1007-1008.

66. Mamie C, Rebsamen MC, Morris MA, Morabia A. First evidence of a polygenic susceptibility to pain in a pediatric cohort. Anesth Analg. 2013;116(1):170-177. 


\section{Supplementary material \\ Recommendations for ambulatory discharge after pediatric tonsillectomy}

1. Preoperative screening

a. Is obstructive sleep apnea severity documented?

i. Polysomnography

1. Consider apnea-hypopnea index threshold for admission (eg, $\mathrm{AHI} \geq 5$ )

2. Consider oxygen saturation nadir threshold (eg, $\left.\mathrm{SpO}_{2} \leq 85 \%\right)$

ii. Clinical predictors for obstructive sleep apnea include loud snoring, daytime somnolence, and apnea observed while asleep

b. Are there important comorbidities?

c. Age

i. If age is $<3$ years, consider close monitoring in recovery for adverse events (especially desaturations, apneas, somnolence, bleeding)

ii. Consider discharge home only after 4-6 hours uncomplicated recovery

iii. Children under 2 years should be admitted routinely due to scant data and overall high risk

d. Other factors to consider

i. Social constraints

ii. Language barriers/comprehension

iii. Access to emergency care/distance from hospital

2. Intraoperative care

a. Any intraoperative events that suggest risk for postoperative complications

i. Difficult airway management

ii. Significant respiratory events: desaturations, laryngospasm, bronchospasm, aspiration of gastric contents

iii. Excessive sensitivity to opiates b. Surgical events:
i. bleeding
ii. vascular injuries

3. Early postoperative care

a. Monitor for respiratory events with continuous pulse oximetry

b. Monitor for excessive sedation

c. Optimize postoperative nausea and vomiting (PONV) prophylaxis and treatment

4. Later recovery concerns
a. Bleeding
b. PONV
c. Dysphagia
d. Dehydration

5. Pain management

a. Minimize opiates

b. Nonsteroidal anti-inflammatory drugs can reduce PONV and opiate requirement

c. Acetaminophen should be started preoperatively and continued around the clock while awake for at least 4 days

d. Ibuprofen appears safe and effective

e. Parents often cannot understand or comply with analgesic plan - provide clear guidance and instructions with specific dosing intervals and amounts

f. Morphine at home may increase risk of 1st-night desaturations and frequency of respiratory events

g. Codeine is no longer recommended for any child after tonsillectomy

h. Adjuncts may be effective though there is minimal evidence for specific recommendations

i. Future genetic analysis may directly quantitate individual sensitivity to specific opiates with improved pain management.
Ambulatory Anesthesia

\section{Publish your work in this journal}

Ambulatory Anesthesia is an international, peer reviewed, open access journal publishing articles that address all aspects of ambulatory anesthesia practice, in particular: anesthetic techniques, sedation and safety practices, pharmacokinetics, preoperative evaluation, analgesia interventions, regulatory and compliance issues, postoperative recovery,

\section{Dovepress}

patient satisfaction, administrative topics, and cost analysis themes. The manuscript management system is completely online and includes a very quick and fair peer review system, which is all easy to use. Visit $\mathrm{http}: / / \mathrm{www}$.dovepress.com/testimonials.php to read real quotes from published authors. 